\title{
Dispatching concrete trucks using simulation method
}

\author{
Sławomir Biruk \\ Katedra Inżynierii Procesów Budowlanych, Wydział Budownictwa i Architektury, \\ Politechnika Lubelska, e-mail: s.biruk@pollub.pl
}

\begin{abstract}
Ready mixed concrete (RMC) is the primary material required for buildings and public infrastructure work. RMC is produced to meet customer's demands and its deliveries must conform to construction site and technological operating constraints - the material cannot be prepared in advance and stored. Concrete production scheduling and truck dispatching is mainly handled manually by experienced $R M C$ batching plants staff. The paper presents simulation model which can be used to asses alternative strategies for truck allocation and production planning in stochastic environment. The models' operation is illustrated by a notional case - the model prompted solutions of improved transhipment efficiency and reduced plant operating cost under assumed operating constraints. ling

Keywords: ready mixed concrete distribution, truck dispatching, simulation model-
\end{abstract}

\section{Introduction}

Ready mixed concrete is a basic construction material used in all components from foundations to roofs, and therefore consumed in large quantities. As many as $60-70 \%$ of all contemporary built structures are made of this material. Due to growing quality requirements and development in concrete mix design aimed at obtaining special qualities of the product, it is manufactured by specialised batching plants in fully controlled environment. The mix is delivered to construction sites by means of ready mixed concrete trucks assuring that the mix keeps its qualities, but the time since mixing till placing is seriously limited: even with retarders, concrete mix sets within several hours. Moreover, concrete mix should be placed continuously to avoid cold joints that reduce strength and quality of concrete members.

This poses a challenge to the mix dispatchers who need to coordinate mix production, transport and placing processes. Most concrete batching plants dispose of advanced automatic production lines able to provide high quality mix in a very short time, but the dispatching process is still based on skills and knowledge of the experienced staff, with little use of computer-based planning [11].

The ready mixed concrete production is a competitive business in a well developed market. With similar material costs, the batching plants search for economies by means of better dispatch control: as the material is relatively cheap and of relatively high transport cost, an integrated system of mix manufacturing, scheduling deliveries and vehicle routing may seriously improve the plant's standing [3]. As the concrete mix expires quickly, a batching plant may serve only those clients who are located in the range that can be reached by trucks within about 1.5 hours. This fact seriously limits the number of potential clients and intensifies competition between plants operating in overlapping areas. Thus, the plants strive for low costs of their product and reliability of their service to stay in the market [2]. 


\section{Ready mixed concrete transportation process}

The time since mixing till placing should be no longer than concrete setting time in particular conditions. To deliver the mix within this "usability window", one has to plan vehicle routes and schedule production so that at the moment that the substrates have been mixed, a truck was ready to collect the mix. Delays and breaks may lead to wasting the whole batch. Having too many trucks queuing for the mix is also not economical.

The mix is a custom-made product: each batch is prepared for a particular client. Therefore, as the batch is loaded into a truck, the truck must be directed to a particular construction site. The dispatcher is in no position to change its destination. Moreover, is quite usual that the construction sites served by a plant are congested or of limited unloading capabilities and cannot receive more than one truck at a time. In this case, to assure continuity of concreting works, the mix production and deliveries need to be scheduled with utmost care.

Feng et al. [2] classify orders for concrete mix in two categories: those placed in advance - at least one day ahead of concrete works, or those placed at the day of concrete works. The latter orders may seriously affect operations of a batching plant, and the dispatcher needs to decide quickly whether accepting such orders is possible and how it affects operating schedules.

The daily demand for the mix is not uniformly distributed. Feng et al. [2] observed that peak hours occur between 9:30 and 11:30 and between 14:30 and 17:00, whereas Matsatsinis [5] and Naso et al. [6] maintain that the demand is clearly higher between 7:00 and 9:00 and later between 13:00 and 15:00. The peak hours are especially challenging for the production, dispatch and transport crews.

\section{Optimisation models of concrete mix dispatching processes}

The integrated system for production and dispatch scheduling is to allow for constraints specific for the concrete mix and fresh concrete. Time is the crucial factor, and this makes mathematical model complex, and optimisation process difficult.

Tommelein and $\mathrm{Li}$ [9] approach this problem as a just-in-time production system. They analyse the mix supply chains with regard to requirements of production process and material qualities, putting forward two models of supply chains. The first one assumes that the plant takes responsibility for the deliveries, the other one transfers all transport tasks to the client (used sometimes for sites located in city centres with strict constraints of noise emission or traffic disturbance - the works must be scheduled for particular hours).

Matsatsinis [5] developed a decision support system for managing two types of means of transport: truck mounted mix pumps and ready mixed concrete trucks. This model was formulated as a multi-depot multi-vehicle routing problem with time windows. The objective function minimizes operating costs of the system and increases service quality level.

Feng et al. [2] investigated in detail into the factors affecting truck routing and scheduling. They proposed a model based on a genetic algorithm and simulation aimed at minimizing truck queuing time. They provided also a user-friendly software facilitating the process of dispatching concrete trucks.

A metaheuristic algorithm for the mix dispatching problem was proposed also Naso et al. [6]. Their model is aimed at minimizing the cost of mix distribution. This cost includes loading, transport, unloading, and additional costs related e.g. with hiring trucks and crew overtime. The model was programmed in Matlab, and its applicability was illustrated by a case of a Dutch batching plant. 
Asbach et al. [1] put forward a mixed linear programming model of mix deliveries with the objective function that minimizes the sum of transport costs and penalties for not fulfilling the order. Due to the model's complexity, it cannot be solved by means of popular solvers, so the authors resorted to their own metaheuristic algorithm and assessed its efficiency.

Park et. al. [7] expanded the scope of modelling from production and dispatch of the mix by allowing for the batching plant supplies with cement and aggregates. The model was solved by means of a customized continuous dynamic simulation system, and a software facilitating operation of the plant was developed and tested in one of plants in Singapore.

Yan et al. [11] integrated scheduling of mix production and vehicle routing. The model is based on time-location diagram with five types of arches to represent operations of the plant and the trucks (truck idle time, truck work, loading or waiting for loading, unloading and returning to the plant, termination of work and returning to the base). The model was then enhanced by allowing for additional constraints: crew overtime cost [13] and traffic-related occurrences [12].

Yan et al. [10] considered that transport time is a random variable. Their dispatching model was formulated as a mixed integer network flow problem with side constraints. The model's applicability was tested by simulations.

Computer simulations were frequently used in the analysis of concrete mix batching plant operations. Wakefield and Sears [14] used Petri Nets, and Zayed and Halpin [15] a Microcyclone network. In both this cases the models were simulated with various resource combination to evaluate productivity of a concrete plant and utilization of equipment. Sobotka et al. [8] used simulation method to reengineer operations of a batching plant. The aim of research was to improve production management by reducing activities that, from the customer's point of view, do not add value to the service. Lu and Lam [4] developed a special-purpose simulation tool for rapid modelling of a typical one-plantmultisite system of concrete production and delivery based on a simplified discrete-event simulation approach. All these attempts speak in favour of applying simulation to assessing and modelling operations of batching plants under a variety of conditions. However, a general model that allows for all identified constraints in random environment.

\section{The simulation model for dispatching concrete trucks}

The author puts forward a simulation model for dispatching concrete trucks aimed at assessing continuity of concreting works in constructions sites and the time since mixing till placing concrete mix. It was programmed with GPSS World discreet simulation language by Minuteman Software. The programme comprises three modules: declaration of input, simulation engine, and collection of simulation data.

The first module requires that the following parameters are defined:

- number of destinations (construction sites) together with their demand for the mix expressed by the number of truckloads to be delivered,

- as-planned start of concrete placing (hour) at each site, given as a delay from the start of a work shift in the site,

- number of available concrete trucks,

- number of concrete mixers at the batching plant (which implies how many trucks can be potentially loaded at the same time),

- distribution type and parameters for truck loading time,

- distribution type and parameters for loaded trucks travel time at the route to each site, 
- distribution type and parameters of truck unloading times in each site,

- distribution type and parameters of the time of empty truck return from each site.

Travelling times depend mostly on the distance between the plant and the site, and the number of crossroads (in urbanized areas). Unloading time depends mostly on the type of concrete member and methods of delivering the mix from the truck to the formworks (by means of pumps, crane skips, dumpers etc.).

The second module (Fig. 1) imitates operations of the concrete trucks and concrete plant. As the shift begins, the trucks (their number is a parameter of the simulation model) queue at the mixers to be loaded. At this point, destinations of the trucks are decided (as well as the product they are loaded with - each site may require a different mix); a variety of strategies may be adopted at this point. For instance, destination of a truck can be chosen in a random manner, or a truck is sent to a site with a shortest queue. Trucks are loaded (loading time) and travel to the sites (travel time), where they form a queue waiting to be unloaded. It was assumed that only one truck can be unloaded at a time. As the unloading process is completed, the truck returns to the plant and, if the demand of the sites was not satisfied yet, they queue for another batch of the mix. The procedure is repeated until all sites receive as much mix as was ordered.

\section{Optimizing the allocation of concrete trucks - an example}

In the analysed case, one batching plant serves five construction sites. Each site has a demand for the mix expressed by the number of truckloads (so the assumption was each batch delivered to each site is of the same volume). These demands are listed in Table 1. The concreting works at each site start at the same time.

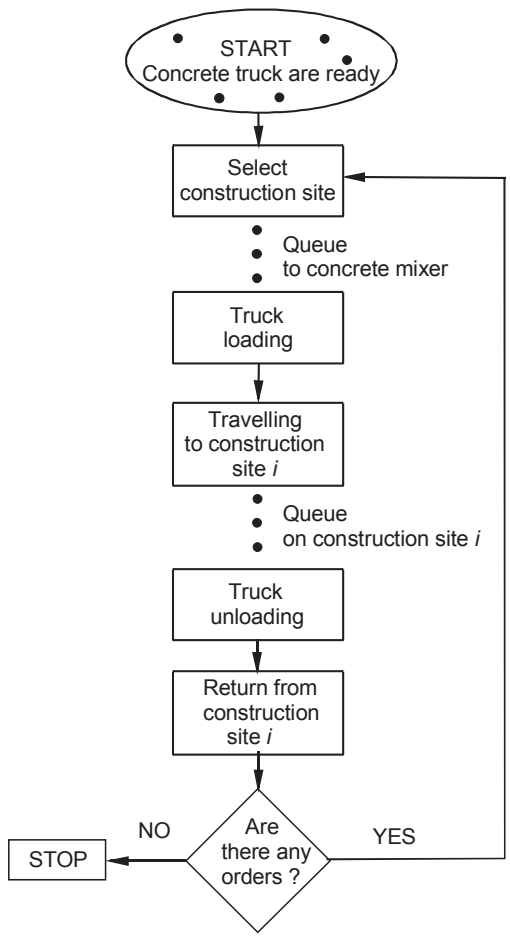

Fig. 1. Diagram of the "simulation engine" 
The plant is equipped with only one mixer, so that only one truck can be loaded at a time. It was assumed that the loading time is a random variable of a triangular distribution defined by the optimistic $\left(t_{a}=5 \mathrm{~min}\right)$, the pessimistic $\left(t_{b}=9 \mathrm{~min}\right)$, and the most likely $\left(t_{m}=\right.$ $6 \mathrm{~min}$ ) values. It was assumed that the components of the transport cycles are also of a triangular distribution with the optimistic, pessimistic and most likely values quoted in Table 1 .

Table 1. Input for the example

\begin{tabular}{ccccc}
\hline Site ID & $\begin{array}{c}\text { Demand for the } \\
\text { mix, truckloads }\end{array}$ & Travel time, minutes & $\begin{array}{c}\text { Unloading time, } \\
\text { minutes }\end{array}$ & $\begin{array}{c}\text { Return time, } \\
\text { minutes }\end{array}$ \\
\hline 1 & 15 & $(12,20,15)$ & $(8,12,9)$ & $(10,17,12)$ \\
\hline 2 & 8 & $(28,45,33)$ & $(6,9,7)$ & $(26,43,31)$ \\
\hline 3 & 12 & $(22,35,26)$ & $(12,18,14)$ & $(19,30,24)$ \\
\hline 4 & 9 & $(15,22,17)$ & $(9,15,11)$ & $(12,20,15)$ \\
\hline 5 & 6 & $(15,25,18)$ & $(8,14,10)$ & $(14,23,17)$ \\
\hline
\end{tabular}

For this simulation, a following strategy was adopted: a loaded truck is directed to the construction site where the truck queue is the shortest. This strategy minimises the time since mixing till placing and assures continuity of concreting in particular sites. In the simulation process, the number of trucks serving the system was change in search for optimum that assures meeting constraints of concreting process with the least number of trucks employed. The simulation results are presented in Fig. 2.

If the maximum acceptable time since mixing till placing is 90 minutes (as for standard mixes at $15^{\circ} \mathrm{C}$ ), the sites must be served by at least 7 trucks. In this case, the batching plant has to work for 558 minutes to cover the demand.

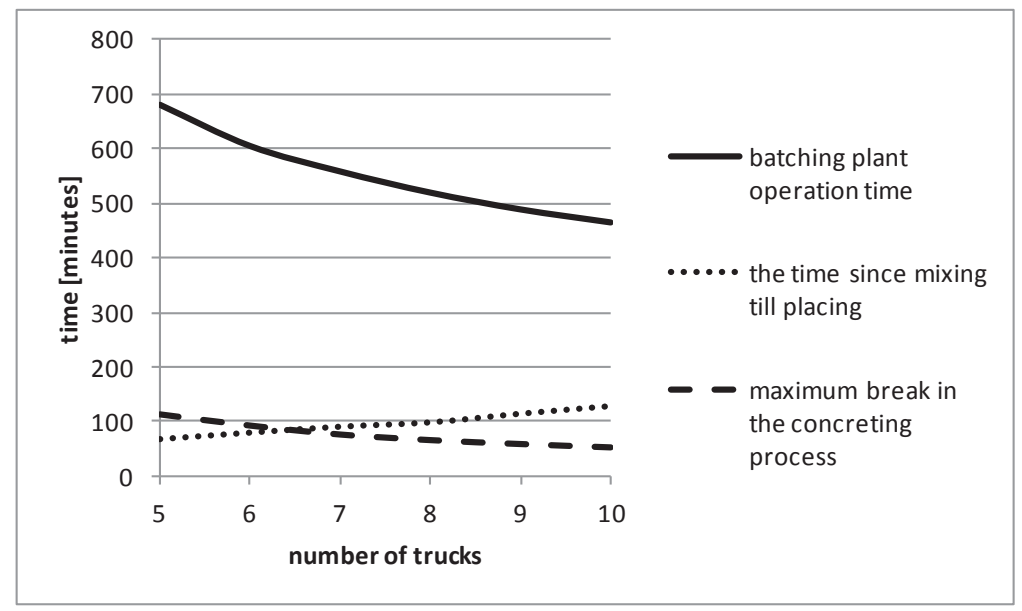

Fig. 2. The relationship between the number of trucks and batching plant operation time, maximum break in the concreting process, and the time since mixing till placing in the analysed case

\section{Conclusions}

Concrete batching plants are typically equipped with modern automated high-capacity systems and provide high quality products. The plants often dispose of fleets of concrete transport trucks. However, the plants rarely use decision support tools to plan transport routes and schedule production of the mix. The decisions in this respect base on experience 
of the staff. The paper investigates into the problems of integrated production scheduling and vehicle routing. Implementing such systems may increase the number of fulfilled orders, improve plant and truck utilisation rates and client satisfaction and, as a result, help to achieve competitive advantage in the highly demanding market of ready mix production.

Further research will be aimed at increasing the number of real-life related constraints as e.g. changes in transport times during the day related with traffic conditions, allowing for availability of trucks and pumps of various capacity. This is aimed at increasing reliability of simulation results.

\section{Acknowledgment}

This work was financially supported by Ministry of Science and Higher Education within the statutory research number S/63/2015

\section{References}

1 Asbach L., Dorndorf U., Pesh E. Analysis, modeling and solution of concrete delivery problem. European Journal of Operational Research 193 (2009) 820-835.

2 Feng Ch. W., Cheng T. M., Wu H. T. Optimizing the schedule of dispatching RMC trucks through genetic algorithms. Automation in Construction 13 (2004) 327-340.

3 Lin P. C., Wang J., Huang S. H., Wang Y. T. Dispatching ready mixed concrete trucks under demand postponement and weight limit regulation. Automation in Construction 19 (2010) 798807.

4 Lu M., Lam H.-C. Simulation - optimization integrated approach to planning ready mixed concrete production and delivery: validation and applications. Proceedings of the 2009 Winter Simulation Conference 2593-2604.

5 Matsatsinis N. F. Towards a decision support system for the ready concrete distribution system: A case of a Greek company. European Journal of Operational Research 152 (2004) 487-499.

6 Naso D., Surico M., Turchiano B., Kaymak U. Genetic algorithms for supply-chain scheduling: A case study in the distribution of ready mixed concrete. European Journal of Operational Research 177 (2007) 2069-2099.

7 Park M., Kim W. Y., Lee H. S., Han S. Supply chain model for ready mixed concrete. Automation in Construction 20 (2011) 44-55.

8 Sobotka A., Biruk S., Jaskowski P. Process approach to production management in a construction company. Proceeding of the Fourth European Conference on Product and Process Modelling in the Building and Related Industries, Portož, Slovenia, 19-11 September 2002.

9 Tommelein I. D., Li A. E. Y. Just-in-time concrete delivery: mapping alternatives for vertical supply chain integration. Proceedings of the Seventh Annual Conference of the International Group for Lean Construction IGLC-7, California 1999, 97-108.

10 Yan S., Lin H. C., Jiang X. Y. A planning model with a solution algorithm for ready mixed concrete production and truck dispatching under stochastic travel times. Engineering Optimization 44 (2012) 427-447.

11 Yan S., Lai W., Chen M. Production scheduling and truck dispatching of ready mixed concrete. Transportation Research. Part E 44 (2008) 164-179.

12 Yan S., Lin H. Ch., Liu Y.-Ch. Optimal schedule adjustments for supplying ready mixed concrete following incidents. Automation in Construction 20 (2011) 1041-1050.

13 Yan S., Lai W. An optimal scheduling model for ready mixed concrete supply with overtime considerations. Automation in Construction 16 (2007) 734-744.

14 Wakefield R., Sears G. Petri Nets for simulation and modeling of construction systems. Journal of Construction Engineering and Management 123(2) (1997) 105-112.

15 Zayed T.M., Halpin D. Simulation of concrete batch plant production. Journal of Construction Engineering and Management 127(2) (2001) 132-141. 